\title{
SOD1 Mutations: More to Learn
}

Can J Neurol Sci. 2012; 39: 132-133

In this issue of the Canadian Journal of Neurological Sciences, Baek et $\mathrm{al}^{1}$ report a novel SOD1 mutation in a case of amyotrophic lateral sclerosis characterized by a slow disease progression. Interestingly the missense mutation was identified in three other asymptomatic members of the family across three generations. The affected amino acid is highly conserved across species and the substitution was predicted to be probably pathogenic by three different bioinformatics programs.

Amyotrophic lateral sclerosis (ALS), commonly named Lou Gehrig's disease or Charcot's disease, is caused by the death of both the upper and lower motor neurons. The first symptoms in ALS patients usually occur during mid-adulthood and typically progress rapidly, usually over a three to five year period, leading to death from failure of respiratory muscles. Familial cases of ALS represent $10 \%$ of all cases. ${ }^{2}$ The majority of patients are considered to be sporadic cases, with no other affected family members.

The cause of neuronal death in ALS is currently unknown, and no treatment to prevent, slow down or stop neurodegeneration exists to date, with the exception of Riluzole, which at best prolongs life by a few months. Over the last decades significant efforts have been deployed to better understand the pathological mechanisms leading to ALS and to eventually develop novel therapeutics. In 1989, genetic analysis using 150 families with ALS identified two regions of possible linkage on chromosomes 11 and $21 .{ }^{3}$ Further evidence of linkage on chromosome 21q22.1-q22.2 was published in 1991, this way identifying the first ALS locus, currently known as ALS $1 .{ }^{4}$ In 1993, an international consortium reported 11 different SOD1 missense mutations in 13 out of 18 dominantly inherited ALS families. ${ }^{5}$ Since then, about 166 disease-causing mutations, 87\% of which are nucleotide substitutions of the encoded protein, have been identified among the 153 amino acids of this fiveexon gene. The remaining $13 \%$ of mutations are deletions, nonsense or splicing mutations, which affect the length of the protein. ${ }^{6-9}$ Even if most SOD1 mutations are transmitted in an autosomal dominant manner, a few families have reduced penetrance or recessive transmission. ${ }^{10}$ Moreover, compound heterozygotes have also been reported, with two different heterozygote SODl mutations in the same patient. ${ }^{11}$ An intriguing report recently described a patient affected with both familial ALS and cerebellar ataxia and an SOD1 mutation. ${ }^{12}$ Rare SOD1 mutated cases with frontotemporal dementia, cognitive impairment, or autonomic dysfunction have also been reported. ${ }^{13-15}$ Interestingly, some substitutions affecting particular SOD1 amino acids are associated with slow disease progression, while other amino acid substitutions, sometimes located in the same region of the gene, are found in patients with a very fast progression. ${ }^{16-18}$ The effect on rate of progression is thought to be related to the fact that some mutants lead to a stable protein while others are highly unstable. ${ }^{9,19-22}$ Approximately 42 mutations have been reported in SALS cases, representing $25 \%$ of the total SODI variation. Fifteen to $20 \%$ of familial cases result from SODI mutations, hence variations in this gene explain about $1-2 \%$ of all ALS cases. ${ }^{5}$

The superoxide dismutase 1 protein (SOD1) is ubiquitously expressed and is mainly located in the cytosol of cells, catalyzing the reduction of the superoxide anion to $\mathrm{O}_{2}$ and $\mathrm{H}_{2} \mathrm{O}$. Most mutations reduce dismutation, ${ }^{23}$ but some have normal or only slightly reduced dismutase activity. ${ }^{20,21}$ Based on the dominant inheritance and the fact that $S O D 1$ knock out mice have no motor neuron phenotype while overexpression of mutant SODI does, it is agreed that mutant SODI acquires a novel cytotoxic function which promotes neurodegeneration. ${ }^{24,25}$ This toxic gain-offunction has been proposed to involve different mechanisms including protein aggregation and misfolding, oxidative stress, mitochondrial dysfunction, microglia activation, glutamate excitotoxicity, and defects in axonal transport. ${ }^{26}$ Specifically, the presence of protein misfolding and aggregation is a recurrent observation in cells of ALS patients, which may inactivate or impair normal processes such as proteasomal degradation or chaperone function. ${ }^{27}$ Some observations also suggest that SODI might be involved in RNA processing. ${ }^{28}$ In addition, SOD1 toxicity has been found to modify wild type SOD1 by inducing it to misfold. ${ }^{29}$ Though extensive research has been conducted to understand the specific pathways involved, it is still unclear how mutant SOD1 leads to the ALS phenotype.

It is intriguing that mutations in the same gene could lead to significantly different disease progression. The missense mutation reported here is located in exon three of the SODI gene, where only a small number of variants have been reported. The affected member of the reported family had slow progression of disease, similar to the ALS phenotype previously associated with another mutation in the same region. ${ }^{30}$ While previous exon three mutations have been mainly associated with a lower motor neuron phenotype, the reported mutation presented here was identified in a patient with mainly upper motor neuron involvement. In addition, the fact that there is currently only one affected individual in this pedigree, no family history and three unaffected mutation carriers, one possibility that must be considered is that this is a non-causative variant. Additional work needs to be done to establish with certainty that the P66S is a disease causing SOD1 mutation. Mutation reports such as this one are essential to better understand the role of genetic variations and understand the pathological pathways involved in the hope to eventually develop effective therapeutics for ALS. 


\section{REFERENCES}

1. Baek W, Koh S-H, Kim YS, et al. A novel exon 3 mutation (P66S) in the SOD1 gene in familial ALS. Can J Neurol Sci. 2012;39(2): 245-6.

2. Camu W, Khoris J, Moulard B, et al. Genetics of familial ALS and consequences for diagnosis. French ALS Research Group. J Neurol Sci. 1999;165 Suppl 1:S21-6.

3. Siddique T, Pericak-Vance MA, Brooks BR, et al. Linkage analysis in familial amyotrophic lateral sclerosis. Neurology. 1989;39: 919-25.

4. Siddique T, Figlewicz DA, Pericak-Vance MA, et al. Linkage of a gene causing familial amyotrophic lateral sclerosis to chromosome 21 and evidence of genetic-locus heterogeneity. N Engl J Med. 1991;324:1381-4.

5. Rosen DR, Siddique T, Patterson D, et al. Mutations in $\mathrm{Cu} / \mathrm{Zn}$ superoxide dismutase gene are associated with familial amyotrophic lateral sclerosis. Nature. 1993;362:59-62.

6. Andersen PM, Sims KB, Xin WW, et al. Sixteen novel mutations in the $\mathrm{Cu} / \mathrm{Zn}$ superoxide dismutase gene in amyotrophic lateral sclerosis: a decade of discoveries, defects and disputes. Amyotroph Lateral Scler Other Motor Neuron Disord. 2003;4: 62-73

7. Valdmanis PN, Belzil VV, Lee $\mathrm{J}$, et al. A mutation that creates a pseudoexon in SOD1 causes familial ALS. Ann Hum Genet. 2009; $73: 652-7$

8. Zinman L, Liu HN, Sato C, et al. A mechanism for low penetrance in an ALS family with a novel SOD1 deletion. Neurology. 2009; 72:1153-9.

9. Birve A, Neuwirth C, Weber M, et al. A novel SOD1 splice site mutation associated with familial ALS revealed by SOD activity analysis. Hum Mol Genet. 2010;19:4201-6.

10. Andersen PM. Amyotrophic lateral sclerosis associated with mutations in the CuZn superoxide dismutase gene. Curr Neurol Neurosci Rep. 2006;6:37-46.

11. Hand CK, Mayeux-Portas V, Khoris J, et al. Compound heterozygous D90A and D96N SOD1 mutations in a recessive amyotrophic lateral sclerosis family. Ann Neurol. 2001;49: 267-71.

12. Yasser S, Fecto F, Siddique T, Sheikh KA, Athar P. An unusual case of familial ALS and cerebellar ataxia. Amyotroph Lateral Scler. 2010;11:568-70

13. Battistini S, Giannini F, Greco G, et al. SOD1 mutations in amyotrophic lateral sclerosis. Results from a multicenter Italian study. J Neurol. 2005;252:782-8.

14. Mase G, Ros S, Gemma A, et al. ALS with variable phenotypes in a six-generation family caused by leu144phe mutation in the SOD1 gene. J Neurol Sci. 2001;191:11-18.

15. Baltadzhieva R, Gurevich T, Korczyn AD. Autonomic impairment in amyotrophic lateral sclerosis. Curr Opin Neurol. 2005;18: 487-93.

16. Del Grande A, Conte A, Lattante S, et al. D11Y SOD1 mutation and benign ALS: a consistent genotype-phenotype correlation. J Neurol Sci. 2011;309:31-3.
17. Juneja T, Pericak-Vance MA, Laing NG, Dave S, Siddique T. Prognosis in familial amyotrophic lateral sclerosis: progression and survival in patients with glu100gly and ala4val mutations in $\mathrm{Cu}, \mathrm{Zn}$ superoxide dismutase. Neurology. 1997;48:55-7.

18. Cudkowicz ME, McKenna-Yasek D, Sapp PE, et al. Epidemiology of mutations in superoxide dismutase in amyotrophic lateral sclerosis. Ann Neurol. 1997;41:210-21.

19. Andersen PM, Nilsson P, Keranen ML, et al. Phenotypic heterogeneity in motor neuron disease patients with $\mathrm{CuZn}$ superoxide dismutase mutations in Scandinavia. Brain. 1997;120 (Pt 10):1723-37.

20. Brotherton T, Polak M, Kelly C, et al. A novel ALS SOD1 C6S mutation with implications for aggregation related toxicity and genetic counseling. Amyotroph Lateral Scler. 2011;12:215-19.

21. Andersen PM, Nilsson P, Ala-Hurula V, et al. Amyotrophic lateral sclerosis associated with homozygosity for an Asp90Ala mutation in CuZn-superoxide dismutase. Nat Genet. 1995;10: 61-6.

22. Prudencio M, Hart PJ, Borchelt DR, Andersen PM. Variation in aggregation propensities among ALS-associated variants of SOD1: correlation to human disease. Hum Mol Genet. 2009;18: 3217-26.

23. Eisen A, Mezei MM, Stewart HG, Fabros M, Gibson G, Andersen PM. SOD1 gene mutations in ALS patients from British Columbia, Canada: clinical features, neurophysiology and ethical issues in management. Amyotroph Lateral Scler. 2008; 9:108-19.

24. Reaume AG, Elliott JL, Hoffman EK, et al. Motor neurons in $\mathrm{Cu} / \mathrm{Zn}$ superoxide dismutase-deficient mice develop normally but exhibit enhanced cell death after axonal injury. Nat Genet. 1996; 13:43-7.

25. Gurney ME, Pu H, Chiu AY, et al. Motor neuron degeneration in mice that express a human $\mathrm{Cu}, \mathrm{Zn}$ superoxide dismutase mutation. Science. 1994;264:1772-5.

26. Rothstein JD. Current hypotheses for the underlying biology of amyotrophic lateral sclerosis. Ann Neurol. 2009;65 Suppl 1: S3-9.

27. Cleveland DW, Rothstein JD. From Charcot to Lou Gehrig: deciphering selective motor neuron death in ALS. Nat Rev Neurosci. 2001;2:806-19.

28. Li X, Lu L, Bush DJ, et al. Mutant copper-zinc superoxide dismutase associated with amyotrophic lateral sclerosis binds to adenine/uridine-rich stability elements in the vascular endothelial growth factor 3'-untranslated region. J Neurochem. 2009;108:1032-44.

29. Ezzi SA, Urushitani M, Julien JP. Wild-type superoxide dismutase acquires binding and toxic properties of ALS-linked mutant forms through oxidation. J Neurochem. 2007;102:170-8.

30. Segovia-Silvestre T, Andreu AL, Vives-Bauza C, Garcia-Arumi E, Cervera C, Gamez J. A novel exon 3 mutation (D76V) in the SOD1 gene associated with slowly progressive ALS. Amyotroph Lateral Scler Other Motor Neuron Disord. 2002;3:69-74. 